\title{
Distress vulnerability and social support in patients with peripheral arterial disease and patients with varicose disease
}

\author{
Liliana Veronica DIACONESCU ${ }^{1}$, Ion DIACONESCU² \\ ${ }^{1}$ Department of Medical Psychology, "Carol Davila“ University of Medicine and \\ Pharmacy, Bucharest, Romania \\ ${ }^{2}$ Department of Vascular Surgery, "Prof. Dr. C.C. Iliescu“ Emergency Institute for \\ Cardiovascular Disease, Bucharest, Romania
}

\begin{abstract}
Introduction. Both peripheral arterial disease (PAD) and varicose disease (VD), as chronic diseases, can generate high levels of emotional distress, with negative affects, which will influence treatment adherence and quality of life.

The study's aim was to analyze the relationship between anxiety, depression, perceived stress and social support in patients with PAD and with VD.

Method. The study included a number of 54 patients (38 men and 16 women) diagnosed with PAD (39 patients) and with VD (15 patients). There were applied (before surgery) psychological tests: Hospital Anxiety and Depression Scale (HADS), Perceived Stress Scale (PSS), The Duke-UNC Functional Social Support Questionnaire (FSSQ).

Results. Women had higher levels of anxiety and depression than men (ns), higher scores on perceived stress scale $(32,94$ vs $29, t=-2,26 ; p<0,028)$, but lower scores on social support scale $(25,50$ vs $30,42, t=2,13$; $p<0,038)$. Patients with PAD had higher scores at anxiety $(10,31$ vs $8,33, t=2,58 ; p<0,012)$, depression $(7,36$ vs $5,40, t=2,05 ; p<0,045)$ and perceived stress $(31$ vs $28, n s)$ and lower scores at social support scale $(27,62$ vs $32,47, t=-2,05 ; p<0,045)$ than patients with VD. Both anxiety and depression positively correlated with perceived stress $(0,639$ respective 0,$410 ; p=0,01)$ and negatively with social support $(-0,574$, respective $-0,522$; $p=0,01)$. Age negative correlated with social support $(-0,464 ; p=0,01)$.

Conclusions. The indication for surgical treatment of vascular disease is a distress factor, leading to anxiety and depression. The increased anxiety at patients with PAD compared with those with VD can be explained by greater severity of this group of diseases, higher surgical risks, more frequent complications and a high risk of amputation. Low social support mainly observed in some elderly patients indicate, on the one hand the restriction of support network at this age and, on the other hand, its usefulness especially in the case of diseases that require surgery and postoperative recovery
\end{abstract}

Keywords: anxiety, depression, social support, peripheral arterial disease, varicose disease

\section{INTRODUCTION}

Within the vascular diseases with surgical treatment indication, peripheral arterial disease (with predominant damage in the lower limbs) and varicose disease (from chronic venous diseases group) are the predominant pathology in vascular surgery departments.
Peripheral arterial disease (PAD) implies damage of arterial blood-axes of the legs; patients suffer of pain during walking (intermittent claudication) or at rest and severe ischemic lesions extending to gangrene and amputation limb-threatening.

Varicose disease (VD) is characterized by the presence of hydrostatic varicose veins of the 
legs with discomfort, swelling of the legs and, in advanced stages, ulcerative lesions.

Both PAD and VD, as chronic diseases, can generate high levels of emotional distress, with negative affects, which will influence treatment adherence and quality of life (1).

Depressive symptoms are present among patients with PAD (2-4), with a prevalence varying between $24 \%$ (5) and $36 \%$, associated with a worse outcome in their revascularized leg (6). Under stressful situations, many of the PAD patients did not feel that social support was given (3).

Depression is prevalent in patients with symptomatic varicose veins, where it is commonly undiagnosed and untreated (7) and can influence the functioning status (8). Depressive symptoms can be associated with enhanced coagulation activation, which was particularly observed if patients perceived levels of social support to be low (9).

The study's aim was to analyze the relationship between anxiety, depression, perceived stress and perceived social support at surgical vascular patients.

\section{MATERIAL AND METHODS}

\section{Participants}

The participants were patients admitted in a vascular surgery department in a period of 6 months during in 2016. The inclusion criteria were the diagnosis of peripheral arterial disease or varicose disease, with surgery indication and without any vascular intervention yet. The criteria were met by 67 patients which, after the informed consent, were instructed how to complete the questionnaires. From them, 54 patients (Table 1 ) returned complete questionnaires.

TABLE 1. Participants in the study

\begin{tabular}{|l|l|c|c|c|}
\hline \multicolumn{2}{|l|}{} & $\begin{array}{c}\text { All patients } \\
\mathbf{N = 5 4}\end{array}$ & $\begin{array}{c}\text { PAD } \\
\mathbf{N = 3 9}\end{array}$ & $\begin{array}{c}\text { VD } \\
\mathbf{N = 1 5}\end{array}$ \\
\hline \multirow{2}{*}{ Age: Mean (SD) } & $\begin{array}{c}54.98 \\
(9.31)\end{array}$ & $\begin{array}{c}58.87 \\
(8.38)\end{array}$ & $\begin{array}{c}50.07 \\
(9.1)\end{array}$ \\
\hline \multirow{2}{*}{ Gender } & Men & 38 & 32 & 6 \\
\cline { 2 - 5 } & Women & 16 & 7 & 9 \\
\hline
\end{tabular}

PAD-peripheral arterial disease; VD-venous disease; SD-standard deviation

\section{Methods}

The study design was transversal. It comprised one single administration (before surgery) of the following questionnaires:

1. Anxiety and Depression Scale (HADS) (10). Is a brief self-report questionnaire (14 items), which assesses anxiety (HADS-A) and depression (HADS-D) as two distinct dimensions in non-psychiatric populations (11). Seven items relate to each dimension, requiring answers on a 4-point scale. It has been used widely in clinical settings where anxiety and depression can co-occur with physical pathology (12).

Characteristics: good internal consistency with Cronbach alpha values ranging from .68 to .93 for HADS-A, and from .67 to .90 for HADS-D (13).

2. Perceived Stress Scale (PSS) (14). Is a 14item self-report instrument, designed to measure "the degree to which situations in one's life are appraised as stressful". It uses 5-point Likert type scales, with total possible scores from 0 to 56 (higher scores represent high stress levels). Characteristics: good convergent validity, indicated by the relationships with depressive ( $r=$ .76, $n=332)$ and physical $(r=.70, n=64)$ symptomatology scales; high internal consistency reliability (Cronbach's alpha = .84 - .86) (15).

3. The Duke-UNC Functional Social Support Questionnaire (FSSQ) (16). Is a 8-item instrument that measures the strength of the person's social support network. Scoring is made on a 1 to 5 scale (the higher the average score, the greater the perceived social support). Characteristics: high construct validity; high internal consistency reliability (Cronbach's alpha $=.81$ $.92)$.

Statistical analysis was carried out using SPSS Statistics 16.0 software. There were used t-test for independent samples, multiple regression analysis and correlations. Statistical significance was considered when $p<0.05$.

\section{RESULTS}

Women (comparing with men) had higher levels of anxiety and depression (ns), higher scores on perceived stress scale, but lower scores on perceived social support scale (Table 2).

PAD patients, in comparison with VD patients, had higher scores at anxiety, depression and perceived stress and lower scores at perceived social support scale (Table 3 ).

We have done several multiple regression analysis in order to evaluate the impact of disease type, patients' gender or age on the levels of anxiety, depression, perceived stress and perceived social support. Three models were considered: model 1 considered as predictor the disease, model 2 included disease type and gender, while model 3 , besides the other two varia- 
TABLE 2. Scores of anxiety, depression, perceived stress and perceived social support at men and women

\begin{tabular}{|c|c|c|c|c|c|}
\hline \multirow[b]{2}{*}{ Study variables } & \multicolumn{3}{|c|}{ Mean (SD) } & \multirow[b]{2}{*}{$t$} & \multirow[b]{2}{*}{$p$} \\
\hline & All participants & $\begin{array}{l}\text { Men } \\
N=38\end{array}$ & $\begin{array}{c}\text { Women } \\
N=16\end{array}$ & & \\
\hline Anxiety & $9.76(2.64)$ & $9.42(2.54)$ & $10.56(2.78)$ & -1.465 & .149 \\
\hline Depression & $6.81(3.23)$ & $6.55(3.25)$ & $7.44(3.20)$ & -.917 & .363 \\
\hline Perceived stress & $30.17(6.05)$ & $29.0(6.19)$ & $32.94(4.82)$ & -2.265 & .028 \\
\hline Perceived social support & 28.96 (7.99) & $30.42(8.4)$ & $25.50(5.78)$ & 2.133 & .038 \\
\hline
\end{tabular}

TABLE 3. Scores of anxiety, depression, perceived stress and perceived social support at PAD and VD patients

\begin{tabular}{|l|c|c|c|c|}
\hline \multirow{2}{*}{ Study variables } & \multicolumn{2}{|c|}{ Mean (SD) } & \multirow{2}{*}{$\boldsymbol{t}$} & $\boldsymbol{p}$ \\
\cline { 2 - 4 } & $\begin{array}{c}\text { PAD patients } \\
\mathbf{N = 3 9}\end{array}$ & $\begin{array}{c}\text { VD patients } \\
\mathbf{N = 1 5}\end{array}$ & $\boldsymbol{t}$ & \\
\hline Anxiety & $10.31(2.74)$ & $8.33(1.71)$ & 2.589 & .012 \\
\hline Depression & $7.36(3.55)$ & $5.40(1.54)$ & 2.054 & .045 \\
\hline Perceived stress & $31.00(6.00)$ & $28.00(5.84)$ & 1.657 & .103 \\
\hline Perceived social support & $27.62(8.21)$ & $32.47(6.39)$ & -2.056 & .045 \\
\hline
\end{tabular}

PAD-peripheral arterial disease; VD-venous disease; SD-standard deviation

bles, included age. The results of regression analysis suggested that for all the studied dependent variables, model 2 (disease type and gender) had the higher predictive value (Table 4).

The correlations (Table 5) carried on showed that both anxiety and depression positively cor- related with perceived stress and negatively with perceived social support. Age negatively correlated with perceived social support.

TABLE 4. Regression analysis for the predictors of anxiety, depression, perceived stress and perceived social support

\begin{tabular}{|c|c|c|c|c|c|}
\hline Dependent variable & Model & Predictor & Beta & $t$ & Sig \\
\hline \multirow{6}{*}{ Anxiety } & 1 & Disease & -.338 & -2.589 & .012 \\
\hline & \multirow{2}{*}{2} & Disease & -.506 & -3.808 & .000 \\
\hline & & Gender & .408 & 3.069 & .003 \\
\hline & \multirow{3}{*}{3} & Disease & -.353 & -2.500 & .016 \\
\hline & & Gender & .294 & 2.175 & .034 \\
\hline & & Age & .321 & 2.463 & .017 \\
\hline \multirow{6}{*}{ Depression } & 1 & Disease & -.274 & -2.054 & .045 \\
\hline & \multirow{2}{*}{2} & Disease & -.393 & -2.762 & .008 \\
\hline & & Gender & .288 & 2.026 & .048 \\
\hline & \multirow{3}{*}{3} & Disease & -.270 & -1.740 & .088 \\
\hline & & Gender & .196 & 1.324 & .191 \\
\hline & & Age & .258 & 1.802 & .078 \\
\hline \multirow{6}{*}{ Perceived stress } & 1 & Disease & -.224 & -1.657 & .103 \\
\hline & \multirow{2}{*}{2} & Disease & -.419 & -3.116 & .003 \\
\hline & & Gender & .472 & 3.515 & .001 \\
\hline & \multirow{3}{*}{3} & Disease & -.308 & -2.094 & .041 \\
\hline & & Gender & .389 & 2.773 & .008 \\
\hline & & Age & .233 & 1.718 & .092 \\
\hline \multirow{6}{*}{ Perceived social support } & 1 & Disease & .274 & 2.056 & .045 \\
\hline & \multirow{2}{*}{2} & Disease & .471 & 3.577 & .001 \\
\hline & & Gender & -.478 & -3.627 & .001 \\
\hline & \multirow{3}{*}{3} & Disease & .331 & 2.341 & .023 \\
\hline & & Gender & -.373 & -2.762 & .008 \\
\hline & & Age & -.295 & -2.267 & .028 \\
\hline
\end{tabular}


TABLE 5. Correlations

\begin{tabular}{|l|c|c|c|c|}
\hline & Anxiety & Depression & Perceived stress & Perceived social support \\
\hline Age & $.484^{*}$ & $.378^{*}$ & $.397^{*}$ & $-.464^{* *}$ \\
\hline Anxiety & & $.509^{* *}$ & $.639^{* *}$ & $-.574^{* *}$ \\
\hline Depression & & & $.410^{* *}$ & $-.522^{*}$ \\
\hline Perceived stress & & & & $-.476^{* *}$ \\
\hline Perceived social support & & & & \\
\hline
\end{tabular}

**. Correlation is significant at the 0.01 level (2-tailed).

*. Correlation is significant at the 0.05 level (2-tailed).

\section{DISCUSSIONS}

Surgical vascular diseases are accompanied by anxiety and depression whose levels are increased in case of indication for surgery treatment.

The higher levels of anxiety and depression at patients with PAD compared with those with VD can be explained by a greater extent of perceived stress due to severity of this group of diseases (higher surgical risks, more frequent complications and a high risk of amputation).

Lower levels of perceived social support at PAD patients may be due to a greater need for help, the disease being more disabling. Low perceived social support, mainly observed in some elderly patients, indicate, on the one hand the restriction of support network at this age and, on the other hand, its usefulness especially in the case of diseases that require surgery and postoperative recovery.

Regarding gender differences, women reported higher levels of perceived stress and lower levels of perceived social support. This aspect is inconsistent with other literature data which show that women have a larger social network capable to offer social support (17). A possible explanation may be that women in our study referred especially to the support given by their family members; gender-centered studies have proven that women usually provide more support to their families than they receive (18).

There are some limitations of the study such as the small number of the participants and the single administration of the tests. The design of the study should have been longitudinal with re- peated administration of the tests at different times (e.g. after the surgery, immediately or after a period of time). Thus, we would have obtained data on the studied variables according to the disease's evolution and/or to its possible complications.

Despite these limitations, our study highlights at least two aspects:

- recognizing the presence of preoperative anxiety and depression at surgical vascular patients which, according with other researchers, were associated with high incidence of complications during the recovery period (19).

- the need to identify protective factors against anxiety and depression; among them social support has beneficial effects such as decreasing anxiety and depression levels and is associated with lower morbidity $(20,21)$.

\section{CONCLUSION}

The above mentioned aspects can be arguments for psychological interventions at these patients. Social support interventions, such as patient support or discussions groups for patients with chronic diseases, aim to increase social support with beneficial effects on psychological adjustment and recovery (22).

\section{Acknowledgements}

The authors would like to thank medical staff of Vascular Surgery Department from Emergency Institute for Cardiovascular Diseases „Prof. Dr. C.C. Iliescu“, Bucharest, who offered us the opportunity to conduct the study.

Conflict of interest: none declared Financial support: none declared 


\section{REFERENCES}

1. Leventhal H., Halm E., Horowitz C. et al. (2005). Living with chronic illness: A contextualized, self-regulation approach, In: S. Sutton, A. Baum \& M. Johnston (Eds), The Sage Handbook of Health Psychology, London, Sage Publications Ltd, 2005:197240.

2. McDermott M.M., Greenland P., Guralnik J.M. et al. Depressive symptoms and lower extremity functioning in men and women with peripheral arterial disease, Journal of General Internal Medicine. 2003;18: 461-467.

3. Remes L., Isoaho R., Vahlberg T. et al. Quality of life among lower extremity peripheral arterial disease patients who have undergone endovascular or surgical revascularization: a case control study, European Journal of Vascular \& Endovascular Surgery. 2010; 40 (5), 618-625.

4. Grenon S.M., Hiramoto J., Smolderen K.G. et al. Association between depression and peripheral artery disease: Insights from the Heart and Soul Study, Journal of the American Heart Association. 2012; 1:e002667 doi: 10.1161/JAHA.112.002667.

5. Arseven A., Guralnik J.M., O'Brien E. et al. Peripheral arterial disease and depressed mood in older men and women, Vascular Medicine. 2001; 6: 229-234.

6. Cherr G.S., Zimmerman P.M., Dosluoglu H.H. Depression is associated with worse patency and recurrent leg symptoms after lower extremity revascularization, Journal of Vascular Surgery. 2007; 45: 744-750.

7. Sritharan K., Lane, T.R.A., Davies, A.H. The burden of depression in patients with symptomatic varicose veins, European
Journal of Vascular \& Endovascular Surgery. 2012; 43 (4): 480-484.

8. Jawien, A., Szewczyk, M.T., KedzioraKornatowska, K. et al. Functional and biopsychosocial restrictions among patients with a venous ulcer, Archives of Medical Sciences. 2006; 2 (1): 36-41.

9. Lukas P.S., Neugebauer A., Schnyder S. et al. Depressive symptoms, perceived social support, and prothrombotic measures in patients with venous thromboembolism, Thrombosis Research. 2012;doi:10.1016/j. thromres.2012.04.011.

10. Zigmond R., Snaith S. (1983) Hospital Anxiety and Depression Scale. Acta Psychiatr. Scand. 1983; 67: 361-370.

11. Herrmann C. International Experiences with the hospital anxiety and depression scale: a review of validation data and clinical results. Journal of Psychosomatic Research, 1997; 42 (1): 17-41.

12. Wilkinson M.J., Barczak P. Psychiatric screening in general practice: comparison of the general health questionnaire and the hospital anxiety depression scale. J R Coll Gen Pract. 1988; 38(312): 311-313.

13. Bjelland I., Dahl A.A., Tangen Haug T., Neckelmann D. The validity of the Hospital Anxiety and Depression Scale: An updated literature review. Journal of Psychosomatic Research. 2002; 52: 69-77.

14. Cohen S., Kamarck T., Mermelstein R. A global measure of perceived stress, Journal of Health and Social Behavior, 1983; 24: 385-396;

15. Levenstein S., Prantera C., Varvo V., Scribano M.L. Development of the Perceived Stress Questionnaire: a new tool for psychosomatic research. Journal of Psychosomatic Research, 1983; 37: 19-32.
16. Broadhead W.E., Gehlbach S.H., DeGruy F.V., Kaplan, B.H. The Duke-UNC Functional Social Support Questionnaire: measurement of social support in family medicine patients, Med. Care. 1988; 26(7): 709-723.

17. Vandervoort D. Social isolation and gender, Current Psychology.2000; 19 (3): 229-236. https://doi.org/10.1007/ s12144-000-1017-5

18. Taylor S.E., Klein L.C., Lewis B.P. et al. Biobehavioral responses to stress in females: Tend-and-befriend, not fight-orflight. Psychological Review. 2000; 107: 411-429.

19. Scavee V., Dehullu J.Ph., Scavee J.P., Michel I. Impact of anxiety in ambulatory superficial venous surgery: A prospective study using thw HADS-A scale, Acta Chirurgica Belgica, 2015; 115 (1): 42-48. http://dx.doi.org/10.1080/00015458 .2015 .11681065

20. Berkman L.F., Glass T.A. Social integration, social networks, social support and health, In: L.F. Berkman \& I. Kawachi (Eds), Social epidemiology, New York: Oxford University Press, 2000; 137-173.

21. Uchino B.N. Social support and health: A review of psychological processes potentially underlying links to disease outcomes, Journal of Behavioral Medicine, 2006; 29 (4), 377-387.

22. Maes S., Boersma S.N. Applications in Health Psychology: How effective are interventions?, In: S. Sutton, A. Baum \& M. Johnston (Eds), The Sage Handbook of Health Psychology, London, Sage Publications Ltd, 2005; 299-325. 